\title{
Conventional Weaning Parameters Do Not Predict Extubation Outcome in Intubated Subjects Requiring Prolonged Mechanical Ventilation
}

\author{
Chun-Ta Huang MD and Chong-Jen Yu MD PhD
}

\begin{abstract}
BACKGROUND: Approaches to respiratory care of patients needing prolonged mechanical ventilation (PMV) might be varied. In this study we assessed the predictive value of usual variables for extubation outcome in PMV patients. METHODS: From 2005 to 2007, intubated patients who were admitted to the intermediate respiratory care unit, had been on mechanical ventilation for $\geq 21$ days at the time of admission, and underwent extubation after successful spontaneous breathing trials were included. Comparisons between subjects with successful extubation and failed extubation in terms of weaning parameters and clinical predictors of extubation outcome were performed. Also, 1-year survival of subjects with regard to extubation outcome was analyzed. RESULTS: Twentyseven $(23.7 \%)$ of 119 PMV subjects required reintubation within 7 days. Multivariate logistic regression analysis demonstrated that the only variable associated with extubation failure was ineffective cough $(P<.001)$. Possessing 2 or more acceptable weaning parameters was not helpful in predicting extubation outcome. Subjects with failed extubation had worse 1-year survival (hazard ratio $0.49,95 \%$ CI $0.28-0.87, P=.02)$ compared with those with successful extubation. CONCLUSIONS: In PMV subjects who tolerated spontaneous breathing trials and were ready to extubate, ineffective cough was the best predictor of extubation failure. Furthermore, extubation failure was associated with future mortality; thus, different management strategies need to be developed for improving patient outcome. Key words: extubation; outcome; predictive index; prolonged mechanical ventilation; intermediate respiratory care unit; weaning. [Respir Care 2013;58(8): 1307-1314. () 2013 Daedalus Enterprises]
\end{abstract}

\section{Introduction}

There is an increasing number of patients requiring prolonged mechanical ventilation (PMV) around the world, because of improved ICU care, population aging, and increased burden of comorbidities. ${ }^{1,2}$ This patient population definitely has different needs and resource utilization patterns from ICU patients, and specialized man-

\footnotetext{
The authors are affiliated with the Department of Internal Medicine and Traumatology, National Taiwan University Hospital, Taipei, Taiwan.

The authors have disclosed no conflicts of interest.

Correspondence: Chong-Jen Yu MD PhD, Department of Internal Medicine, National Taiwan University Hospital, 7 Chung-Shan South Road, Taipei 100 Taiwan. E-mail: jefferycjyu@ntu.edu.tw.
}

DOI: $10.4187 /$ respcare. 01773 agement strategies for them are rapidly emerging. ${ }^{3}$ Accordingly, different approaches to respiratory care might be indicated. ${ }^{3}$

In the past few years, the importance of predicting extubation outcome following a successful spontaneous breathing trial (SBT) has been emphasized. Nowadays it is realized that predicting the outcome of an SBT is less important because an SBT is easy to perform, safe, and well tolerated. ${ }^{4}$ Several studies have identified a number of clinical factors predicting extubation failure in the ICU setting. ${ }^{4-6}$ However, it remains uncertain whether the performance of these factors can be reproduced for PMV patients.

The aim of the present study was to test the predictive value of the usual variables for extubation outcome in PMV patients in a specialized intermediate respiratory care unit (IRCU) setting. Also, the 1-year survival of the patients with regard to extubation outcome was analyzed. 


\section{Conventional Weaning Parameters Do Not Predict Extubation Outcome}

\section{Methods}

\section{Study Setting}

This retrospective study was conducted in the 12-bed IRCU at the National Taiwan University Hospital, Yunlin, Taiwan, a university-affiliated hospital. In Taiwan, an integrated delivery system program driven by National Health Insurance Bureau has, since 1998, been applied in patients who are expected to require ventilatory support for $\geq 21$ days. Patients were eligible for IRCU admission if they met the following requirements: hemodynamic stability, no vasoactive drug infusion, stable oxygen requirements, no active hepatic or renal failure, no requirement for surgical intervention, or the primary physician deemed it beneficial for the patient to be transferred to the IRCU. The nurse-to-patient ratio in the IRCU was 1:4, and respiratory-therapist-to-patient ratio was 1:12. All subjects received continuous pulse oximetry, electrocardiogram, and impedance pneumography monitoring.

\section{Study Subjects With Prolonged Mechanical Ventilation}

From January 2005 to December 2007, all patients who had been intubated and on mechanical ventilation for $\geq 21$ days at the time of admission to the IRCU and were extubated following a successful SBT during the IRCU stay were identified in the respiratory care database. All subjects were followed for 1 year after IRCU admission or until death. Subjects who were lost to follow-up within 1 year after IRCU admission were included in the analysis of extubation outcome but were excluded from survival analysis. The study was approved by the research ethics committee of the institution, and requirement for informed consent was waived.

\section{Extubation Outcome}

The definition of extubation failure was the inability to sustain spontaneous breathing within 7 days after removal of the endotracheal tube, according to the recommendation of the National Association for Medical Direction of Respiratory Care. ${ }^{3}$ Otherwise, the subjects were classified as successful extubation. Subjects who required immediate reintubation because of upper-airway obstruction after extubation were excluded from the analysis.

\section{Data Collection}

Clinical information was obtained from the respiratory care database and medical records. Variables retrieved included demographics, severity of illness as determined by

\section{QUICK LOOK}

\section{Current knowledge}

An increasing number of patients require prolonged mechanical ventilation following critical illness, which is associated with high healthcare costs. Discontinuing mechanical ventilation in these patients remains a challenge.

\section{What this paper contributes to our knowledge}

In prolonged mechanical ventilation patients who passed a spontaneous breathing trial and were considered ready for extubation, ineffective cough was the single best predictor of extubation failure, and extubation failure was associated with poor outcome.

the Acute Physiology and Chronic Health Evaluation (APACHE) II score on IRCU admission, comorbidities, medical or surgical type of ICU admission, causes of respiratory failure, ICU stay, ventilator days, failed trials of extubation before IRCU admission, and initial ventilatory settings on IRCU admission.

Weaning parameters and risk factors previously associated with extubation failure were obtained from the respiratory $\log$ sheets and medical records. For the purpose of this study, only weaning parameters, including breathing frequency, minute ventilation, tidal volume, and maximum inspiratory pressure, recorded on the day of and prior to the SBT with subsequent attempted extubation, were obtained. ${ }^{7}$ The rapid shallow breathing index (RSBI) was derived by dividing the breathing frequency by the tidal volume. Risk factors for extubation failure, including level of consciousness as determined by the Glasgow coma scale score, effectiveness of cough, volume and character of airway secretions, and fluid balance as determined by fluid input minus output over the 24-hour period, were recorded during the 24 hours before extubation. ${ }^{4,5}$ The effectiveness of cough was classified as effective (strong cough with phlegm moving into the endotracheal tube) or ineffective (no cough response or audible movement of air through the endotracheal tube but no audible cough). ${ }^{8}$ The volume of airway secretions was classified as abundant (requiring suctioning every 2 hours or less) or not abundant (requiring less frequent suctioning), ${ }^{8}$ and character of airway secretions was classified as purulent or non-purulent. The information regarding the assessment of cough effectiveness was retrieved across the 3 nursing shifts within 24 hours before extubation. If there were discordant results, they were categorized according to the dominant classification. 


\section{Conventional Weaning Parameters Do Not Predict Extubation Outcome}

\section{Weaning Protocol}

A respiratory-therapist-implemented weaning protocol, which was adapted from the statement of the sixth international consensus conference on intensive care medicine, was used in the IRCU. ${ }^{9}$ In brief, daily screening for weaning and SBT readiness was performed by respiratory therapists, and an SBT was conducted on T-piece or lowlevel pressure support for 30-120 min at the discretion of the respiratory therapist if the subject fulfilled the following criteria: reliable respiratory drive, stable hemodynamic status, no deterioration of the offending disease, PEEP $\leq 8 \mathrm{~cm} \mathrm{H} \mathrm{H}_{2} \mathrm{O}, \mathrm{F}_{\mathrm{IO}_{2}} \leq 0.40$, and RSBI of $<200$. RSBI was evaluated from measurements of the minute ventilation and breathing frequency while subjects breathed through the ventilator circuit with CPAP of $5 \mathrm{~cm} \mathrm{H}_{2} \mathrm{O}$. The measurements were obtained using the Wright spirometer attached to the expiratory port of the ventilator circuit, and were made after a 1-2 min equilibration period was allowed to elapse after stopping the ventilator. SBT was considered successful if none of the following signs or symptoms was observed at the end of the SBT: breathing frequency $>35$ breaths/min, arterial oxygen saturation $<90 \%$, heart rate $>140$ beats/min or a sustained increase or decrease of heart rate of $>20 \%$, systolic blood pressure of $>180 \mathrm{~mm} \mathrm{Hg}$ or $<90 \mathrm{~mm} \mathrm{Hg}$, anxiety, agitation, diaphoresis, or thoracoabdominal asynchrony. ${ }^{10}$ The primary physician ordered extubation for all subjects who succeeded the SBT. If this was the case, he or she was immediately extubated after the SBT.

\section{Statistical Analysis}

Results are expressed mean \pm SD or proportions, as appropriate. The inter-group differences were compared by using the independent samples $t$ test for continuous variables, and the chi-square test or Fisher exact test for categorical variables, as appropriate. A 2-tailed $P$ value of $<.05$ was used to indicate statistical significance. All statistical analyses were performed using statistics software (SPSS 15.0, SPSS, Chicago, Illinois).

To estimate the effects of multiple variables on extubation outcome, a multivariate analysis was performed using a logistic regression model. Weaning parameters were coded as dichotomous variables, using established cutoff values. ${ }^{7}$ All tested variables were entered into the model despite their insignificant levels in the univariate analysis. In addition, the possible influence of the number of acceptable weaning parameters on extubation outcome was analyzed. Acceptable weaning parameters were defined as follows: breathing frequency $<30$ breaths/min, minute ventilation $\leq 10 \mathrm{~L} / \mathrm{min}$, tidal volume $\geq 5 \mathrm{~mL} / \mathrm{kg}$, RSBI $<105$, and maximum inspiratory pressure $\geq-20 \mathrm{~cm} \mathrm{H}_{2} \mathrm{O}{ }^{7}$

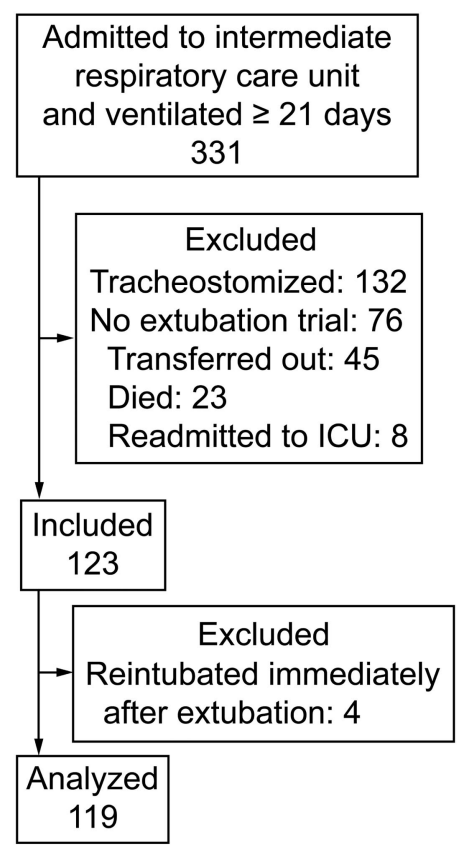

Fig. 1. Flow diagram showing patient selection and exclusion.

Survival curves for subjects with successful extubation and failed extubation were plotted using the Kaplan-Meier method, and compared by the log-rank test. The Cox proportional hazards model was used to determine the relationship between 1-year survival and subject characteristics, including extubation outcome, age, sex, APACHE II score, and ICU stay, which were coded as dichotomous variables using the median values, as appropriate. ${ }^{11,12}$

\section{Results}

\section{Subject Characteristics}

During the 3-year period, a total of 357 subjects were admitted to the IRCU, and 93\% (331/357) of them had been placed on mechanical ventilation for $\geq 21$ days at IRCU admission, accounting for $11.5 \%$ (331/2886) of all ventilated ICU subjects. Of those, 123 subjects were included in this study (Fig. 1). There were 132 tracheostomized subjects excluded; 97 (73.5\%) of them had a tracheostomy done before IRCU transfer, including 4 undergoing tracheostomy prior to this episode of respiratory failure. The median time to tracheostomy insertion for the 128 subjects was 21 days during this hospitalization. Four subjects who were reintubated immediately because of acute upper-airway obstruction after extubation were excluded from the data analysis. Table 1 shows the baseline characteristics of the study cohort. The mean age of the subjects was 77 years, and approximately half of them were male. The average APACHE II score on IRCU 


\section{Conventional Weaning Parameters Do Not Predict Extubation Outcome}

Table 1. Characteristics of Subjects at Admission to the Intermediate Respiratory Care Unit

\begin{tabular}{|c|c|c|c|c|}
\hline & $\begin{array}{l}\text { Subjects } \\
n=119\end{array}$ & $\begin{array}{l}\text { Successful } \\
\text { Extubation } \\
n=92\end{array}$ & $\begin{array}{l}\text { Failed } \\
\text { Extubation } \\
n=27\end{array}$ & $P$ \\
\hline Age, mean $\pm \mathrm{SD}$ y & $77 \pm 14$ & $77 \pm 14$ & $78 \pm 11$ & .58 \\
\hline Male, no. (\%) & $56(47)$ & $46(50)$ & $10(37)$ & .24 \\
\hline APACHE II score, mean \pm SD & $15 \pm 6$ & $15 \pm 5$ & $16 \pm 7$ & .44 \\
\hline \multicolumn{5}{|l|}{ Comorbidities, no. (\%) } \\
\hline Chronic kidney disease & $54(45)$ & $39(42)$ & $15(56)$ & .23 \\
\hline Cerebrovascular disease & $53(45)$ & $40(44)$ & $13(48)$ & .67 \\
\hline Diabetes mellitus & $46(39)$ & $32(35)$ & $14(52)$ & .11 \\
\hline Congestive heart failure & $28(24)$ & $23(25)$ & $5(19)$ & .49 \\
\hline Obstructive airway disease & $25(21)$ & $21(23)$ & $4(15)$ & .37 \\
\hline ICU admitting diagnosis, no. (\%) & & & & .96 \\
\hline Medical & $93(78)$ & $72(77)$ & $21(78)$ & \\
\hline Surgical & $26(22)$ & $20(22)$ & $6(22)$ & \\
\hline Predominant cause of respiratory failure, no. (\%) & & & & .39 \\
\hline Pneumonia & $47(40)$ & $33(36)$ & $14(52)$ & \\
\hline Postoperative state & $15(13)$ & $12(13)$ & $3(11)$ & \\
\hline Sepsis & $15(13)$ & $13(14)$ & $2(7)$ & \\
\hline Post-resuscitation & $11(9)$ & $9(10)$ & $2(7)$ & \\
\hline Coma & $10(8)$ & $9(10)$ & $1(4)$ & \\
\hline COPD & $6(5)$ & $6(7)$ & $0(0)$ & \\
\hline Heart failure & $5(4)$ & $4(4)$ & $1(4)$ & \\
\hline ARDS & $3(3)$ & $1(1)$ & $2(7)$ & \\
\hline Other & $7(6)$ & $5(5)$ & $2(7)$ & \\
\hline $\mathrm{ICU}$ days, mean $\pm \mathrm{SD} \mathrm{d}$ & $26 \pm 9$ & $26 \pm 6$ & $27 \pm 15$ & .59 \\
\hline Ventilator days, mean $\pm \mathrm{SD} d$ & $25 \pm 6$ & $25 \pm 6$ & $25 \pm 6$ & .82 \\
\hline Documented failed extubations, no. (\%) & & & & .40 \\
\hline 0 & $87(73)$ & $70(76)$ & $17(63)$ & \\
\hline 1 & $29(24)$ & $20(22)$ & $9(33)$ & \\
\hline$>1$ & $3(3)$ & $2(2)$ & $1(4)$ & \\
\hline Ventilator modes, no. (\%) & & & & .50 \\
\hline PSV & $76(64)$ & $60(65)$ & $16(59)$ & \\
\hline SIMV/PSV & $20(17)$ & $13(14)$ & $7(26)$ & \\
\hline PCV & $15(13)$ & $12(13)$ & $3(11)$ & \\
\hline VCV & $8(7)$ & $7(8)$ & $1(4)$ & \\
\hline $\begin{array}{l}\text { APACHE }=\text { Acute Physiology and Chronic Health Evaluation } \\
\text { PSV = pressure-support ventilation } \\
\text { SIMV = synchronized intermittent mandatory ventilation } \\
\text { PCV = pressure controlled ventilation } \\
\text { VCV = volume controlled ventilation }\end{array}$ & & & & \\
\hline
\end{tabular}

admission was 15 . The most common comorbidities were chronic kidney disease $(45 \%)$, cerebrovascular disease $(45 \%)$, and diabetes mellitus $(39 \%)$. Three quarters of the subjects were admitted to the ICU with a medical diagnosis, and the primary indications for mechanical ventilation were pneumonia $(40 \%)$, postoperative respiratory failure $(13 \%)$, and sepsis $(13 \%)$. The mean ICU stay and ventilator days were 26 days (range 21-97 d) and 25 days (range 21-48 d), respectively. A large proportion (73\%) of the subjects did not undergo an extubation trial during the ICU stay, and two thirds of the subjects were ventilated in the pressure support ventilation mode on admission to the IRCU.

\section{Outcome After Extubation and Predictors for Reintubation}

After IRCU transfer, 29 (24.4\%) subjects succeeded their first SBT attempt and were extubated. Overall, $3.3 \pm$ 2.3 SBT attempts were needed before the subjects underwent extubation. On average, the subjects were extubated 12 days after admission to the IRCU. Ninety percent (107/119) of the subjects passed an SBT with T-piece, and $78.5 \%(84 / 107)$ of them were successfully extubated. On the other hand, $10 \%(12 / 119)$ of the subjects passed the SBT with low-level pressure support, and $66.7 \%(8 / 12)$ of them were successfully extubated. Statistical analysis 


\section{Conventional Weaning Parameters Do Not Predict Extubation Outcome}

Table 2. Performance of Parameters Previously Associated With Extubation Failure in Subjects With Prolonged Mechanical Ventilation

\begin{tabular}{|c|c|c|c|}
\hline & $\begin{array}{c}\text { Successful } \\
\text { Extubation } \\
n=92 \\
\text { no. }(\%)\end{array}$ & $\begin{array}{c}\text { Failed } \\
\text { Extubation } \\
n=27 \\
\text { no. }(\%)\end{array}$ & $\begin{array}{c}\text { Multivariate } \\
P\end{array}$ \\
\hline Breathing frequency $\geq 30$ breaths $/ \mathrm{min}$ & $46(50)$ & $15(56)$ & .61 \\
\hline Minute ventilation $>10 \mathrm{~L} / \mathrm{min}$ & $49(53)$ & $14(52)$ & .90 \\
\hline Tidal volume $<5 \mathrm{~mL} / \mathrm{kg}$ & $27(29)$ & $10(37)$ & .45 \\
\hline $\mathrm{RSBI} \geq 105$ & $42(46)$ & $14(52)$ & .57 \\
\hline $\mathrm{P}_{\text {Imax }}<-20 \mathrm{~cm} \mathrm{H}_{2} \mathrm{O}$ & $9(10)$ & $2(7)$ & $>.99$ \\
\hline Glasgow coma scale score $\leq 10$ & $65(71)$ & $18(67)$ & 69 \\
\hline Ineffective cough & $27(29)$ & $23(85)$ & $<.001$ \\
\hline Abundant airway secretions & $8(9)$ & $2(7)$ & $>.99$ \\
\hline Purulent airway secretions & $31(34)$ & $9(33)$ & .97 \\
\hline Positive fluid balance & $22(24)$ & $10(37)$ & .18 \\
\hline $\begin{array}{l}\mathrm{RSBI}=\text { rapid shallow breathing index } \\
\mathrm{P}_{\mathrm{Imax}}=\text { maximum inspiratory pressure }\end{array}$ & & & \\
\hline
\end{tabular}

showed that the mode of SBT did not have any effect on extubation outcome. Overall, about one quarter $(27 / 119$, $23.7 \%$ ) of the subjects required reintubation within 7 days of extubation; of those, only 5 (18.5\%) needed reintubation because of the development of a new disease process, including acute coronary syndrome $(n=1)$, arrhythmia $(n=1)$, aspiration $(n=1)$, massive upper gastrointestinal hemorrhage $(n=1)$, and pneumonia $(n=1)$. Of note, one third $(9 / 27,33.3 \%)$ of subjects who failed extubation were reintubated 3-7 days post-extubation (Fig. 2). Subjects with successful extubation had a similar mean IRCU stay before extubation trials $(12.1 \pm 7.8 \mathrm{~d}$ vs $11.0 \pm 8.7 \mathrm{~d})$, compared with subjects with failed extubation. About the effectiveness of cough, total agreement of the data obtained across 3 nursing shifts could be achieved in $83 \%$ of the subjects. In the multivariate logistic regression model, cough effectiveness was the only

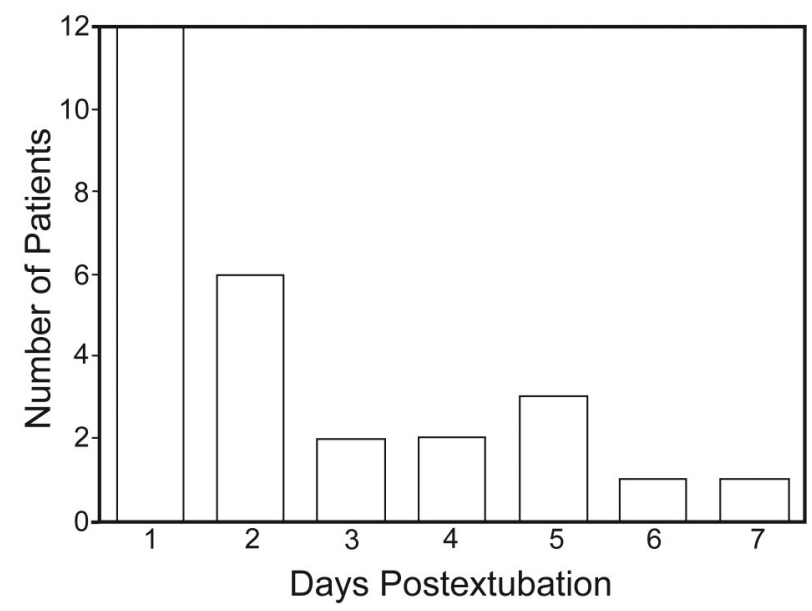

Fig. 2. Number of patients reintubated within 7 days of extubation. variable independently predicting extubation outcome of these subjects (Table 2). The sensitivity, specificity, positive predictive value, and negative predictive value of ineffective cough as a predictor of failed extubation were $85 \%, 71 \%, 46 \%$, and $94 \%$, respectively. Table 3 indicates that the number of acceptable weaning parameters did not predict extubation outcome; more than half of the subjects who failed extubation had at least 3 acceptable weaning parameters.

\section{Long-Term Survival}

The in-hospital mortality of all 119 subjects was $24.4 \%$. Seven subjects lost to follow-up at 1 year were excluded from the survival analysis. The 1-year survival of subjects

Table 3. Correlation Between Number of Acceptable Weaning Parameters and Extubation Outcome in Subjects With Prolonged Mechanical Ventilation

\begin{tabular}{|c|c|c|c|}
\hline $\begin{array}{l}\text { Number of } \\
\text { Acceptable } \\
\text { Weaning } \\
\text { Parameters* }\end{array}$ & $\begin{array}{l}\text { Successful } \\
\text { Extubation } \\
\quad n=92 \\
\text { no. }(\%)\end{array}$ & $\begin{array}{c}\text { Failed } \\
\text { Extubation } \\
n=27 \\
\text { no. }(\%)\end{array}$ & $P$ \\
\hline \multirow[t]{2}{*}{5} & $19(21)$ & $5(19)$ & .81 \\
\hline & 73 (79) & $22(82)$ & \\
\hline \multirow[t]{2}{*}{4} & 36 (39) & $9(33)$ & .59 \\
\hline & $56(61)$ & $18(67)$ & \\
\hline \multirow[t]{2}{*}{3} & $58(63)$ & $15(56)$ & .48 \\
\hline & $34(37)$ & $12(44)$ & \\
\hline \multirow[t]{2}{*}{2} & $82(89)$ & $24(89)$ & $>.99$ \\
\hline & $10(11)$ & 3 (11) & \\
\hline $\begin{array}{l}\text { * Acceptable we } \\
\leq 10 \mathrm{~L} / \mathrm{min} \text {, tida } \\
\text { inspiratory press }\end{array}$ & $\begin{array}{l}\text { ters: breathing } \mathrm{f} \\
5 \mathrm{~mL} / \mathrm{kg} \text {, rapid } \\
\mathrm{m} \mathrm{H}_{2} \mathrm{O} \text {. }\end{array}$ & $\begin{array}{l}30 \text { breaths } / \mathrm{min} \text {, } \\
\text { thing index }<1\end{array}$ & $\begin{array}{l}\text { ilation } \\
\text { imum }\end{array}$ \\
\hline
\end{tabular}




\section{Conventional Weaning Parameters Do Not Predict Extubation Outcome}

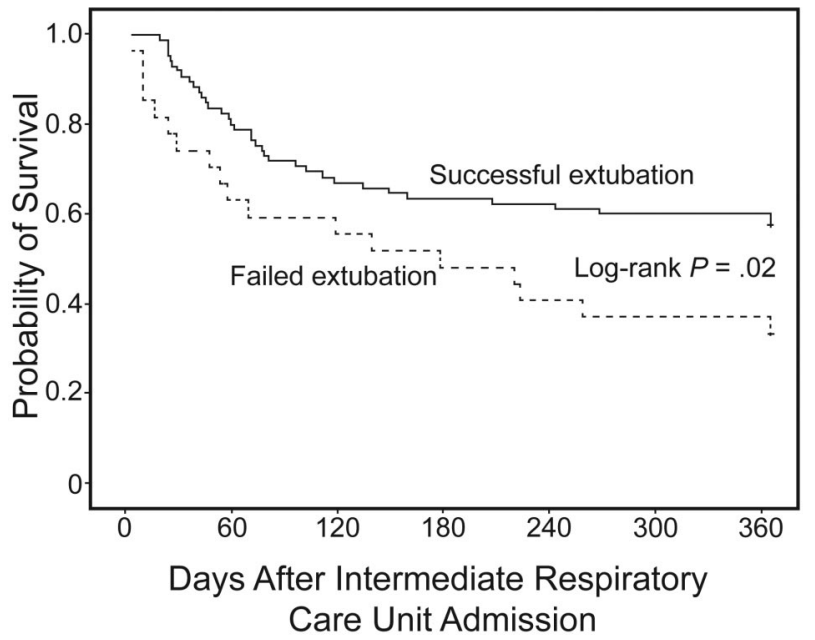

Fig. 3. Kaplan-Meier curves of 1-year survival since intermediate respiratory care unit admission, stratified by extubation outcome.

Table 4. Cox Proportional Hazards Model Incorporating Extubation Outcome, Age, Sex, Apache II Score, and ICU Days as Potential Predictors of 1-Year Survival

\begin{tabular}{lccc}
\hline \multicolumn{1}{c}{ Characteristic } & $\begin{array}{c}\text { Hazard } \\
\text { Ratio }\end{array}$ & $95 \%$ CI & $P$ \\
\hline Successful vs failed extubation & 0.49 & $0.28-0.87$ & .02 \\
Age $<79$ y vs $\geq 79$ y & 1.13 & $0.65-1.97$ & .67 \\
Female vs male sex & 0.81 & $0.47-1.41$ & .46 \\
APACHE II score $<15$ & 0.65 & $0.37-1.15$ & .14 \\
$\quad$ vs $\geq 15$ & & & \\
ICU stay $<23$ d vs $\geq 23$ d & 0.89 & $0.51-1.53$ & .66
\end{tabular}

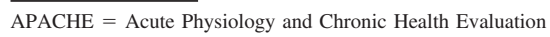

with successful extubation was significantly better than that of subjects with failed extubation (Fig. 3). There were 77, 67, and 61 subjects seen at 3-, 6-, and 12-month follow-up, respectively. A Cox proportional hazards model incorporating subject demographics, severity of illness, and extubation outcome showed that failed extubation remained an independent predictor of worse long-term survival (Table 4). Instead, age, sex, APACHE II score, and ICU stay did not have a discriminative value for 1-year survival of these IRCU subjects.

\section{Discussion}

This study shows that among the usual predictors of extubation outcome, cough effectiveness was the only one independently predicting extubation outcome of intubated PMV subjects in an IRCU setting, and failed extubation independently predicted a worse 1-year survival.

Nowadays it remains difficult to predict extubation outcome in ICU patients. Similarly, in this study we were unable to identify predictive variables achieving enough sensitivity and specificity to be reliably used as a sole predictor of extubation outcome in PMV subjects. Studies have demonstrated the importance of cough strength as a factor related to reintubation. ${ }^{13,14}$ On multivariate analysis, we also showed that ineffective cough was more common in subjects who failed extubation, and its positive predictive value and negative predictive value in predicting failed extubation were $46 \%$ and $94 \%$, respectively. The result indicates that, although many PMV subjects were successfully extubated despite poor airway clearance function, the presence of effective cough was highly associated with successful extubation. The present study extends the importance of airway competence on extubation outcome to PMV subjects recovering from a variety of medical and surgical illnesses. However, given the study design, we were not allowed to provide an objective measure of cough strength to be used in the decision to extubate.

The finding of an association between failed extubation and a higher mortality rate is not new ${ }^{15,16}$; however, to our knowledge this is the first study to demonstrate this association in an IRCU setting. The probability of survival in 27 subjects who failed their first extubation trial was approximately half that of those who succeeded extubation (see Table 4). Because 2 survival curves obviously separated within 2 months of IRCU admission (see Fig. 3), failed extubation might impose some negative effects on these subjects. First, it has been suggested that reintubation is harmful because it increases the risk of pneumonia, ${ }^{16}$ and the study by Torres et al in a mixed medicalsurgical ICU found that approximately half of the mortality rate among reintubated subjects was attributable to the development of pneumonia. ${ }^{16}$ Second, clinical deterioration might occur during the interval between extubation and reintubation and contribute to worse outcome.

Furthermore, although adjustments were made for severity of illness, the possibility that failed extubation represents an independent marker of more severe illness could not be excluded. This way, failed extubation itself would provide additional prognostic information to that derived from conventional severity scores. Taken together, no matter what the exact relationship is between failed extubation and patient outcome, our study suggests that alternative dedicated care practices should be instituted with the aim of reducing mortality when taking care of PMV patients who fail extubation trials.

In the present study, the reintubation rate was $23.7 \%$, which seemed higher than previously reported rates of $10-20 \%{ }^{4,5,17,18}$ The difference was caused by various study settings (ICU vs IRCU), patient populations (medical vs surgical vs mixed medical-surgical), and, most importantly, definitions of successful extubation $(48-72 \mathrm{~h}$ vs 7 d). PMV patients usually have slower recovery of respiratory function and complex chronic comorbidities; thus, 


\section{Conventional Weaning Parameters Do Not Predict Extubation Outcome}

the definition of successful extubation is certainly confounded by differences in patient characteristics. A significant proportion of our subjects who failed extubation were reintubated beyond 72 hours after extubation. Besides, most subjects required reintubation because of the original respiratory process. Therefore, in agreement with the recommendation by National Association for Medical Direction of Respiratory Care, ${ }^{3}$ this work suggests that sustaining spontaneous breathing for 7 consecutive days should constitute successful extubation in PMV patients.

The RSBI was first described by Yang and Tobin in $1991,{ }^{19}$ and early studies suggested that it was the most accurate predictor of failure in weaning patients from mechanical ventilation. ${ }^{20,21}$ However, in the past decade a few possible limitations of the RSBI used during the weaning process were demonstrated. First, it mainly gauges the ability to sustain spontaneous breathing without the ventilator, but does not help distinguish extubation outcome..$^{8,22}$ Second, the RSBI tends to be higher in PMV patients, probably because these chronically ill patients are more likely to assume a rapid shallow breathing respiratory pattern, due to muscle wasting and weakness, and does not predict weaning outcome in these patients. ${ }^{23,24}$ Accordingly, it is not surprising that the present study did not find an association between the RSBI and extubation outcome in the IRCU setting.

Severity scoring systems were originally derived and designed for use in the ICU setting to assess severity of illness and predict mortality; however, their accuracy of predicting long-term mortality in a post-ICU setting has not been thoroughly validated. Consistent with prior studies, ${ }^{11,25}$ we did not demonstrate an association between long-term survival and the APACHE II score. Although such an association has been reported in a few studies, ${ }^{24,26,27}$ they primarily investigated mortality over a short period of time, and found that the APACHE II score was poor at discriminating between individual patients in terms of risk of death. ${ }^{27}$ Development of a severity scoring system for PMV patients is important because these patients consume a disproportionate amount of healthcare resources and have high medical costs. ${ }^{28,29}$ Such a scoring system could facilitate earlier and more definitive discussions between physicians and patients/surrogates regarding appropriate goals of care. Thus, defining adequately performing and validated severity measures is urgently needed.

Compared to studies conducted in western countries, 30,31 in which tracheostomy was performed after a median of approximately 2 weeks of mechanical ventilation, half of the 128 tracheostomized PMV patients who were not eligible for this study underwent tracheostomy after more than 3 weeks of ventilatory support. Cultural differences may account for the discrepancy. In our practice the decision to proceed to tracheostomy is usually made if the patient cannot be extubated within 14 days; however, pa- tients and their families tend to refuse or postpone the procedure because by custom Asian cultures disapprove of creating a stoma in the body. Actually, the optimal timing for tracheostomy in PMV patients remains a point of debate. There is conflicting evidence about whether early tracheostomy improves outcomes for PMV patients. 24,32 In this regard, the timing of tracheostomy should be individualized according to ongoing assessment of a patient's progress, readiness to wean, and preference.

There are several limitations to this study. First, the data were collected in a specialized IRCU, and the study subjects were intubated and required PMV. Thus, the results might not be universally applied to all subjects receiving PMV. Second, because of the design of this study, we are able to draw conclusions regarding associations but not causation. Third, the relatively small number of subjects limits statistical power, particularly in comparison between successfully and unsuccessfully extubated subjects, as the number of subjects in the latter group is even smaller. Finally, although total agreement of the cough effectiveness assessment between nurses was observed in the majority of the subjects, we could not evaluate the reliability and reproducibility of the assessment of cough in this retrospective study. Further investigations are needed to validate our results.

\section{Conclusions}

In a cohort of PMV subjects who passed an SBT and were considered clinically appropriate for extubation, we demonstrate that ineffective cough was the single best predictor of extubation failure, and there was an association between extubation failure and adverse patient outcome. This indicates that there is still much unknown about the determinants of extubation outcome in patients with PMV, and more work is needed to broaden our understanding of the issue. In addition, extubation failure is associated with future mortality; thus, different management strategies should be established to improve patient outcome.

\section{REFERENCES}

1. Carson SS, Cox CE, Holmes GM, Howard A, Carey TS. The changing epidemiology of mechanical ventilation: a population-based study. J Intensive Care Med 2006;21(3):173-182.

2. Carson SS. Outcomes of prolonged mechanical ventilation. Curr Opin Crit Care 2006;12(5):405-411.

3. MacIntyre NR, Epstein SK, Carson S, Scheinhorn D, Christopher K, Muldoon S; National Association for Medical Direction of Respiratory Care. Management of patients requiring prolonged mechanical ventilation: report of a NAMDRC consensus conference. Chest 2005; 128(6):3937-3954

4. Frutos-Vivar F, Ferguson ND, Esteban A, Epstein SK, Arabi Y, Apezteguía C, et al. Risk factors for extubation failure in patients following a successful spontaneous breathing trial. Chest 2006;130(6): 1664-1671. 


\section{Conventional Weaning Parameters Do Not Predict Extubation Outcome}

5. Mokhlesi B, Tulaimat A, Gluckman TJ, Wang Y, Evans AT, Corbridge TC. Predicting extubation failure after successful completion of a spontaneous breathing trial. Respir Care 2007;52(12):1710-1717.

6. Esteban A, Alía I, Gordo F, Fernandez R, Solsona JF, Vallverdú I, et al. Extubation outcome after spontaneous breathing trials with T-tube or pressure support ventilation. The Spanish Lung Failure Collaborative Group. Am J Respir Crit Care Med 1997;156(2 Pt 1):459-465.

7. MacIntyre N. Discontinuing mechanical ventilatory support. Chest 2007;132(3):1049-1056.

8. Khamiees M, Raju P, DeGirolamo A, Amoateng-Adjepong Y, Manthous CA. Predictors of extubation outcome in patients who have successfully completed a spontaneous breathing trial. Chest 2001;120(4):1262-1270.

9. Boles JM, Bion J, Connors A, Herridge M, Marsh B, Melot C, et al. Weaning from mechanical ventilation. Eur Respir J 2007;29(5): 1033-1056.

10. Esteban A, Frutos F, Tobin MJ, Alía I, Solsona JF, Valverdú I, et al. A comparison of four methods of weaning patients from mechanical ventilation. The Spanish Lung Failure Collaborative Group. N Engl J Med 1995;332(6):345-350.

11. Aboussouan LS, Lattin CD, Kline JL. Determinants of long-term mortality after prolonged mechanical ventilation. Lung 2008;186(5): 299-306.

12. Pilcher DV, Bailey MJ, Treacher DF, Hamid S, Williams AJ, Davidson AC. Outcomes, cost and long term survival of patients referred to a regional weaning centre. Thorax 2005;60(3):187-192.

13. Smina M, Salam A, Khamiees M, Gada P, Amoateng-Adjepong Y, Manthous CA. Cough peak flows and extubation outcomes. Chest 2003;124(1):262-268.

14. Salam A, Tilluckdharry L, Amoateng-Adjepong Y, Manthous CA. Neurologic status, cough, secretions and extubation outcomes. Intensive Care Med 2004;30(7):1334-1339.

15. Epstein SK, Ciubotaru RL, Wong JB. Effect of failed extubation on the outcome of mechanical ventilation. Chest 1997;112(1):186-192.

16. Torres A, Gatell JM, Aznar E, el-Ebiary M, Puig de la Bellacasa J, Gonzalez J, et al. Re-intubation increases the risk of nosocomial pneumonia in patients needing mechanical ventilation. Am J Respir Crit Care Med 1995;152(1):137-141.

17. Epstein SK. Decision to extubate. Intensive Care Med 2002;28(5): 535-546.

18. Epstein SK. Extubation failure: an outcome to be avoided. Crit Care 2004;8(5):310-312.

19. Yang KL, Tobin MJ. A prospective study of indexes predicting the outcome of trials of weaning from mechanical ventilation. $\mathrm{N}$ Engl J Med 1991;324(21):1445-1450.
20. Chatila W, Jacob B, Guaglionone D, Manthous CA. The unassisted respiratory rate-tidal volume ratio accurately predicts weaning outcome. Am J Med 1996;101(1):61-67.

21. Jacob B, Chatila W, Manthous CA. The unassisted respiratory rate/ tidal volume ratio accurately predicts weaning outcome in postoperative patients. Crit Care Med 1997;25(2):253-257.

22. Su WL, Chen YH, Chen CW, Yang SH, Su CL, Perng WC, et al. Involuntary cough strength and extubation outcomes for patients in an ICU. Chest 137(4):777-782.

23. Wu YK, Kao KC, Hsu KH, Hsieh MJ, Tsai YH. Predictors of successful weaning from prolonged mechanical ventilation in Taiwan. Respir Med 2009;103(8):1189-1195.

24. Wu YK, Tsai YH, Lan CC, Huang CY, Lee CH, Kao KC, et al. Prolonged mechanical ventilation in a respiratory-care setting: a comparison of outcome between tracheostomized and translaryngeal intubated patients. Crit Care 2010;14(2):R26.

25. Schonhofer B, Euteneuer S, Nava S, Suchi S, Kohler D. Survival of mechanically ventilated patients admitted to a specialised weaning centre. Intensive Care Med 2002;28(7):908-916.

26. Quality of Life After Mechanized Ventilation in the Elderly Study Investigators. 2-month mortality and functional status of critically ill adult patients receiving prolonged mechanical ventilation. Chest 2002; 121(2):549-558.

27. Carson SS, Bach PB. Predicting mortality in patients suffering from prolonged critical illness: an assessment of four severity-of-illness measures. Chest 2001;120(3):928-933.

28. Zilberberg MD, Luippold RS, Sulsky S, Shorr AF. Prolonged acute mechanical ventilation, hospital resource utilization, and mortality in the United States. Crit Care Med 2008;36(3):724-730.

29. Robson V, Poynter J, Lawler PG, Baudouin SV. The need for a regional weaning centre, a one-year survey of intensive care weaning delay in the Northern Region of England. Anaesthesia 2003;58(2): 161-165.

30. Scheinhorn DJ, Hassenpflug MS, Votto JJ, Chao DC, Epstein SK, Doig GS, et al. Post-ICU mechanical ventilation at 23 long-term care hospitals: a multicenter outcomes study. Chest 2007;131(1):85-93.

31. Esteban A, Anzueto A, Alía I, Gordo F, Apezteguía C, Pálizas F, et al. How is mechanical ventilation employed in the intensive care unit? An international utilization review. Am J Respir Crit Care Med 2000;161(5):1450-1458.

32. Clec'h C, Alberti C, Vincent F, Garrouste-Orgeas M, de Lassence A, Toledano D, et al. Tracheostomy does not improve the outcome of patients requiring prolonged mechanical ventilation: a propensity analysis. Crit Care Med 2007;35(1):132-138.

This article is approved for Continuing Respiratory Care Education credit. For information and to obtain your CRCE

(free to AARC members) visit

www.rcjournal.com

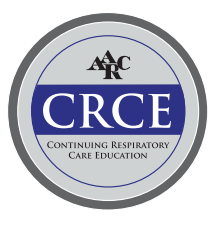

